\title{
DETERMINATION OF QUALITATIVE WORKING INDICES OF EQUIPMENT FOR DECONTAMINATION OF HORTICULTURAL PRODUCT EXTERIOR SURFACES USING OZONE IN AQUEOUS SOLUTION
}

\author{
Cristian Sorica, Ion Pirna, Elena Sorica, Ion Grigore \\ National Institute of Research-Development for Machines and \\ Installations Designed to Agriculture and Food Industry, Romania \\ cri_sor2002@yahoo.com
}

\begin{abstract}
In fresh state, fruits and vegetables might be subjected to some optional pathogenic microorganisms such as bacteria, yeasts and molds. The activity of these microorganisms upon horticultural products can conduct to losses within the storage process or even food-borne diseases with effects on consumer health. In this respect, a low microbiological load at the beginning of the refrigeration process is a must in order to obtain a bigger acceptable duration for the storage of the horticultural products. Within various decontamination methods used for this purpose, the use of ozone has a great potential. In gaseous or in aqueous solution, ozone is used to reduce microbial populations as an alternative to chemical decontamination, being approved for use as an antimicrobial agent in food in 2001 (US FDA). As an antimicrobial agent, ozone leaves no residues, completely broken down into diatomic oxygen in a period between 2 and 30 minutes. The oxidation capacity of ozone is 1.5 times higher than chlorine and 3,000 times higher than that of hypochlorous acid $(\mathrm{HOCl})$. The contact times required for carrying antimicrobial action are usually 4-5 times lower than in the case of chlorine. In this context, the paper presents experimental researches on the possibility of using ozone in aqueous solution, within the conditioning technologies of horticultural products, by investigating the qualitative working indices of an experimental model of equipment for decontamination of horticultural product exterior surfaces.
\end{abstract}

Keywords: post-harvest treatment, aqueous ozone, decontamination.

\section{Introduction}

Although they contain much less energy substances than animal products, horticultural products are important for their contribution in vitamins, minerals, fibres, enzymes, aromatic volatile substances, etc., contributing to the proper conduct of metabolic processes in the human body. As a result of the role they have in nutrition, these products are part of the food ration at the rate of $20-25 \%$.

In general, throughout the technology chain for obtaining food products, from harvest (or production) to consumption product loss can reach values between 30 and $80 \%$ of the total production, depending on the nature of the product, its marketing, consumption habits, climatic conditions, etc. The main causes of these losses are: mechanical actions (structural degradation by crushing), drying processes, aging (especially for fruit) and degrading actions of pests (microflora, rodents, birds, etc.). In foodstuffs of plant origin, microflora is represented especially by bacteria, molds and yeasts.

The activity of these microorganisms upon horticultural products can conduct to losses within the storage process or even food-borne diseases with effects on consumer health. In the case of horticultural products, losses caused by the decay process might reach 10-50 \% level, depending on the temporary storage facilities.

In order to obtain an acceptable, as long as possible time period of storage for refrigerated products, it is necessary to ensure both at the beginning and during refrigeration a microbial load as small as possible. This requires minimizing the possibilities of microbial contamination of products at all stages of pre-refrigeration as well as during this process.

Sterilization of food using conventional thermal methods is unsuitable for horticultural products consumed fresh since the heat causes irreversible changes in colour, smell, flavour and a loss of nutritional value [1].

The conventional antimicrobial treatments for fresh horticultural products are based on chemical compounds and physical contact in order to inactivate and remove bacterial contamination. For the reduction of microbial contamination, chlorine-based cleaning systems have been widely used.

Nowadays, there is a major interest in developing new methods for safe and efficient decontamination of horticultural products [2]. In this respect, there have been various alternative 
disinfectants (hydrogen peroxide, organic acids and ozone) tested in order to reduce bacterial populations [3-4].

In the modern preservation methods, ozone decontamination has great potential. This is a very powerful oxidizing agent, which has been safely used in disinfecting water for various applications. Recent applications include wastewater treatment, water systems and equipment in hospitals [5-7], aquariums and aquaculture, water theme parks, surfaces cleaning, fruit and vegetable washing and processing, fruit and vegetable storage, etc.

Unlike other antimicrobial chemical agents, ozone leaves no residues, completely broken down into diatomic oxygen in a period between 2 and 30 minutes.

Ozone, in gaseous form or in aqueous solution, is used to reduce microbial populations in food products, as an alternative to chemical decontamination, being classified in 1982 as a product generally recognized as safe [8] and in 2001 it was approved by the Food and Drug Administration (US FDA) for use as an antimicrobial agent in food products [9]. As an antimicrobial agent, ozone has an oxidation capacity 1.5 times higher than chlorine and 3,000 times higher than that of hypochlorous acid $(\mathrm{HOCl})$. The contact times required for carrying antimicrobial action are usually 4-5 times lower than in the case of chlorine.

Ozone has previously been evaluated for the control of various diseases arising in the post-harvest and for other uses, especially in storage (removes ethylene, purifies the air, removes odours) [10-14]. Some commercial uses were recorded for some products such as apples, cherries, carrots, onions and potatoes.

The use of ozone as an anti-microbial agent within processes such as post-harvest treatment, storage and food processing has recently come to the forefront. Nowadays ozone is used as a safe and powerful disinfectant to control microbial populations in products and equipment used in the food and beverage industries. In aqueous solution, ozone can be used to disinfect equipment, process water, and some food products. In gaseous form, ozone helps sanitize and assist in the preservation of certain food products, and it is also used to sanitize food packaging materials [15].

\section{Materials and methods}

Among the microorganisms that were subjected to ozone treatment in air or water, those, shown in Table 1, are included. For the destruction of these optional pathogenic microorganisms, which could eventually contaminate horticultural products, with adverse effect on storage or human health, certain doses of ozone are necessary to be applied.

Optional pathogenic microorganisms and necessary ozone doses [16]

Table 1

\begin{tabular}{|c|c|c|}
\hline Microorganism & Reduction, \% & $\begin{array}{c}\text { Dose (CT value), } \\
\text { mg.min. } \mathbf{I}^{\mathbf{1}}\end{array}$ \\
\hline \multicolumn{3}{|c|}{ Bacteria } \\
\hline Bacillus Bacteria & 100 & 0.1 \\
\hline Bacillus cereus & 99 & 0.6 \\
\hline Escherichia coli & 99.99 & 0.4 \\
\hline Mycobacterium avium & 99.9 & 0.17 \\
\hline Salmonella typhimurium & 99.99 & 0.42 \\
\hline \multicolumn{3}{|c|}{ Molds } \\
\hline Botrytis cinerea & 100 & 7.6 \\
\hline Cladosporium & 90 & 1.21 \\
\hline Fusarium oxysporum S.sp. lycopersici & 100 & 0.07 \\
\hline \multicolumn{3}{|c|}{ Viruses } \\
\hline Bacteriophage F2 & 99.99 & 0.4 \\
\hline Enterovirus Virus & 100 & 0.4 \\
\hline Stomatitis Virus & 100 & 0.4 \\
\hline Vesicular Virus & 100 & \\
\hline
\end{tabular}


Given the above issues, the experimental researches on the possibility of using ozone in aqueous solution, within the conditioning technologies of horticultural products, have focused on investigating the qualitative working indices of an experimental model of equipment for the decontamination of horticultural product exterior surfaces. In this respect, new technical equipment was experimented (Fig. 1) - Equipment for decontamination with ozone in aqueous solution, EDO, designed and manufactured within INMA Bucharest.

The equipment used for the decontamination with ozone in aqueous solution of horticultural product external surfaces as preliminary stage for the post-harvesting treatment with UV-C radiation and temporary storage phase itself, comprises the following main assemblies: frame - pos. 1, transport system - pos. 2, collection table - pos. 3, supply cuvette - pos. 4, ozone treatment tunnel - pos. 5, collection basin - pos. 6 , ozone exhaust system - pos. 7 , ozone generation system - pos. 8 and distribution system for ozone in aqueous solution - pos. 9 .

The transport system performs the transportation of the product along the equipment and also the rotation of it around an axis perpendicular to the direction of advance. In this way a homogeneous distribution of the ozone is assured in aqueous solution upon the exterior surfaces of the products. The aqueous ozone is purged upon the products moving on the transport system of the machine using a set of 3 nozzles with conical distribution and square spray pattern.

The ozone generation system is based on the corona discharge effect in the coaxial electrodes system, using oxygen obtained from the atmospheric air, through an oxygen concentrator, the type column with molecular sieve, renewable by purging the nitrogen and water vapors detained on its surface.

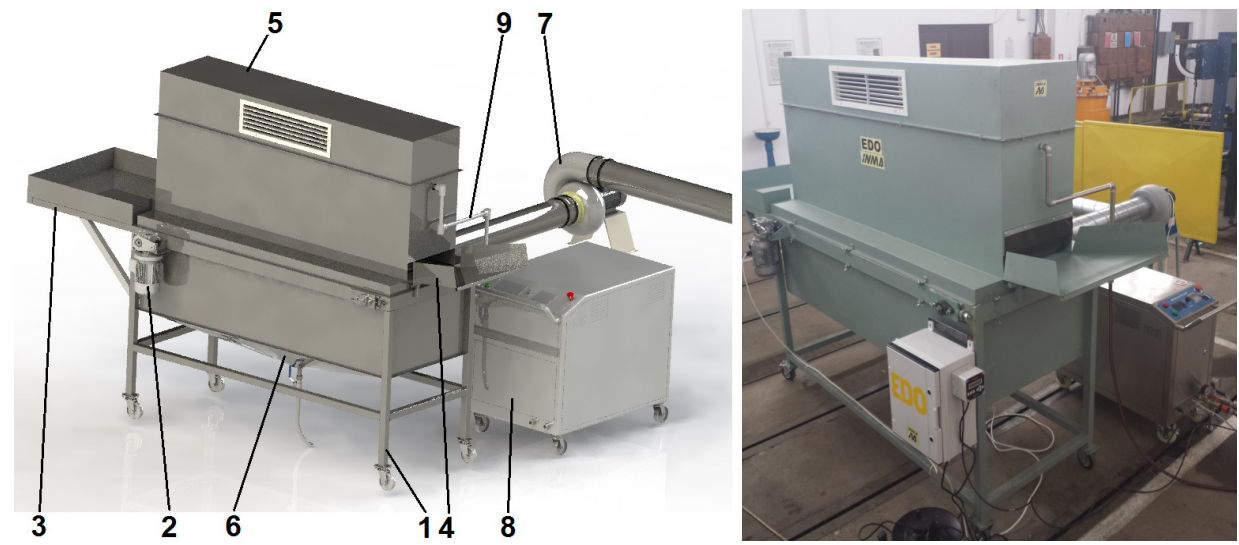

Fig. 1. Equipment for decontamination with ozone in aqueous solution, EDO: 3D model - left side; physical model - right side

The main technical characteristics of the decontamination equipment are the following.

- Working width:400 mm.

- Length of the transport system: $1525 \mathrm{~mm}$.

- Length of the ozone distribution zone along the transport system $1200 \mathrm{~mm}$.

- Ozone generator type: corona discharge.

- Ozone production: 0.5-3.0 $\mathrm{g} \mathrm{O}_{3} \cdot \mathrm{h}^{-1}$.

- Dissolved ozone concentration: 1-2 ppm.

- Minimum inlet water pressure: 1.5 bar.

- Mass (without tubing and ventilator): $210 \mathrm{~kg}$.

The experimental researches have the goal to determine the qualitative working indices of the decontamination equipment. For this purpose, the following parameters were taken into account.

- The rotational speed of the driving system of the conveyor was determined by measurement, considering the variation of supply current frequency of the gear-motor, using the frequency converter currently existing within the automation installation.

- The transport time was determined by measuring the time needed for a product subjected to decontamination to pass one length of the transport system. 
- The transport speed was determined using the length of the transport system and the transport time.

- The flow rate of the spray nozzle was determined by measuring the volume of liquid passing through the nozzle in one minute.

In order to determine the dissolved ozone concentration measurements were performed using a process analyser for ozone, Thermo Fisher Scientific brand, USA, comprising of the following elements: a dissolved ozone sensor "AnalogPlus" and a universal analyser "AV88".

Determinations at different frequencies of the supply current of the gear-motor were performed. The aim was to highlight the influence of various parameters (frequency of the supply current of the gear-motor, rotational speed, transport time, transport speed and contact time) on the applied ozone dose. The ozone dose represents the concentration of dissolved ozone, applied during the contact time. In order to determine the applied ozone dose the following equation was used:

$$
D=C \cdot T \text {, }
$$

where $C$-dissolved ozone concentration, $\mathrm{mg} \cdot \mathrm{l}^{-1}$;

$T$ - contact time (transport time), min.

The contact time was determined considering the transport speed of the product and the length of the ozone distribution zone along the transport system using the following equation:

$$
T=\frac{1}{60} \cdot \frac{L_{\text {Ozone }}}{v_{i}},
$$

where $L_{\text {Ozone }}-$ length of the ozone distribution zone along the transport system, m; $v_{i}-$ transport speed, $\mathrm{m} \cdot \mathrm{s}^{-1}$.

To determine the coefficient of variation for the distribution of the volume of liquid sprayed along the length of the transport system, the following equation was used:

$$
\mathrm{C} V_{\text {flow }}=100 \cdot \frac{\sigma_{\text {flow }}}{V_{m}},
$$

where $\sigma_{\text {flow }}-$ standard deviation of the volumes collected from nozzles in one minute;

$V_{m}$ - average volume collected from nozzles in one minute.

The standard deviation of the volumes collected from nozzles was determined using the following equation:

$$
\sigma_{\text {flow }}=\sqrt{\frac{\sum\left(V_{i}-V_{m}\right)^{2}}{n-1}},
$$

where $V_{i}$ - volume of liquid collected from the nozzle ,i” in one minute;

$n$ - number of nozzles.

The coefficient of variation for the distribution of the volume of liquid sprayed along the length of the transport system, is a quality indicator for the spraying process and represents the ratio between the standard deviation and the average, expressed in percents. It points out the homogenity of the values obtained and also the level of dispersion towards the average. Practically, this indicator shows if the spraying nozzles are properly calibrated by the producer and homogeneously distribute the liquid.

\section{Results and discussion}

Following the analysis of the experimental data, a series of results have been obtained regarding the qualitative indices of the decontamination equipment. These results are presented in Table 2 and Table 3. 
Qualitative indices related to the volume of liquid sprayed by nozzle

\begin{tabular}{|c|c|c|c|}
\hline $\begin{array}{c}\text { Nozzle } \\
\text { no. }\end{array}$ & $\begin{array}{c}\text { Average volume } \\
\text { per nozzle, } \mathbf{~}\end{array}$ & $\begin{array}{c}\text { Average } \\
\text { volume, } \mathbf{~}\end{array}$ & $\begin{array}{c}\text { Coefficient of variation for the } \\
\text { distribution of the volume, \% }\end{array}$ \\
\hline 1 & 1.893 & \multirow{2}{*}{1.891} & \\
\cline { 1 - 2 } & 1.888 & & 0.15 \\
\hline 3 & 1.893 & & \\
\hline
\end{tabular}

Table 2

Qualitative indices related to the applied ozone dose

\begin{tabular}{|c|c|c|c|c|c|c|c|}
\hline \multirow{2}{*}{$\begin{array}{c}\text { Frequency, } \\
\mathbf{H z}\end{array}$} & \multirow{2}{*}{$\begin{array}{l}\text { Rotational } \\
\text { speed, } \\
\text { rot·min }\end{array}$} & \multicolumn{2}{|c|}{ Transport time } & \multirow{2}{*}{$\begin{array}{c}\text { Transpo } \\
\text { rt speed, } \\
\mathrm{m} \cdot \mathrm{s}^{-1}\end{array}$} & \multirow{2}{*}{$\begin{array}{c}\text { Contact } \\
\text { time, } \\
\text { min }\end{array}$} & \multirow{2}{*}{$\begin{array}{c}\text { Dissolved } \\
\text { ozone con- } \\
\text { centration, } \\
\mathrm{mg}^{-1} \mathrm{l}^{-1}\end{array}$} & \multirow{2}{*}{$\begin{array}{c}\text { Applied } \\
\text { ozone dose, } \\
\text { mg } \cdot \min \cdot \mathbf{l}^{-1}\end{array}$} \\
\hline & & $\begin{array}{c}\text { Time, } \\
\text { s }\end{array}$ & $\begin{array}{l}\text { Standard } \\
\text { error of the } \\
\text { average, } s\end{array}$ & & & & \\
\hline 5 & 5.9 & 35.37 & 0.58 & 0.043 & 0.465 & \multirow{10}{*}{1.32} & 0.614 \\
\hline 10 & 14.1 & 14.56 & 0.48 & 0.105 & 0.191 & & 0.252 \\
\hline 15 & 21.7 & 9.15 & 0.37 & 0.167 & 0.120 & & 0.158 \\
\hline 20 & 28.9 & 6.80 & 0.47 & 0.224 & 0.089 & & 0.118 \\
\hline 25 & 36.3 & 5.68 & 0.27 & 0.269 & 0.074 & & 0.098 \\
\hline 30 & 43.7 & 4.52 & 0.20 & 0.337 & 0.059 & & 0.078 \\
\hline 35 & 51.2 & 4.45 & 0.26 & 0.343 & 0.058 & & 0.077 \\
\hline 40 & 58.5 & 3.77 & 0.11 & 0.405 & 0.049 & & 0.065 \\
\hline 45 & 65.8 & 3.68 & 0.04 & 0.414 & 0.048 & & 0.063 \\
\hline 50 & 73.2 & 2.71 & 0.08 & 0.563 & 0.036 & & 0.048 \\
\hline
\end{tabular}

The average volume per nozzle from Table 2 is obtained from three repetitions for each nozzle. Also, the transport time values from Table 3 represent the average of three repetitions for each value obtained during experimentation. Since the applied ozone dose depends only on the dissolved ozone concentration, which is considered constant within some limits (depending mainly on the pressure, flow rate and the temperature of the water, quality of atmospheric air used for gazeous ozone production, pressure drop caused by the distribution system etc.), and the contact time, we will present the variation of the contact time with various parameters involved within the process (Fig. 2). Even if the contact time is directly correlated with those parameters (frequency of the supply current of the gear-motor, rotational speed and transport time) and the laws of variation are known, the graphical reprezentation shows, visualy, these dependencies and could give a quick overview of the entire process.

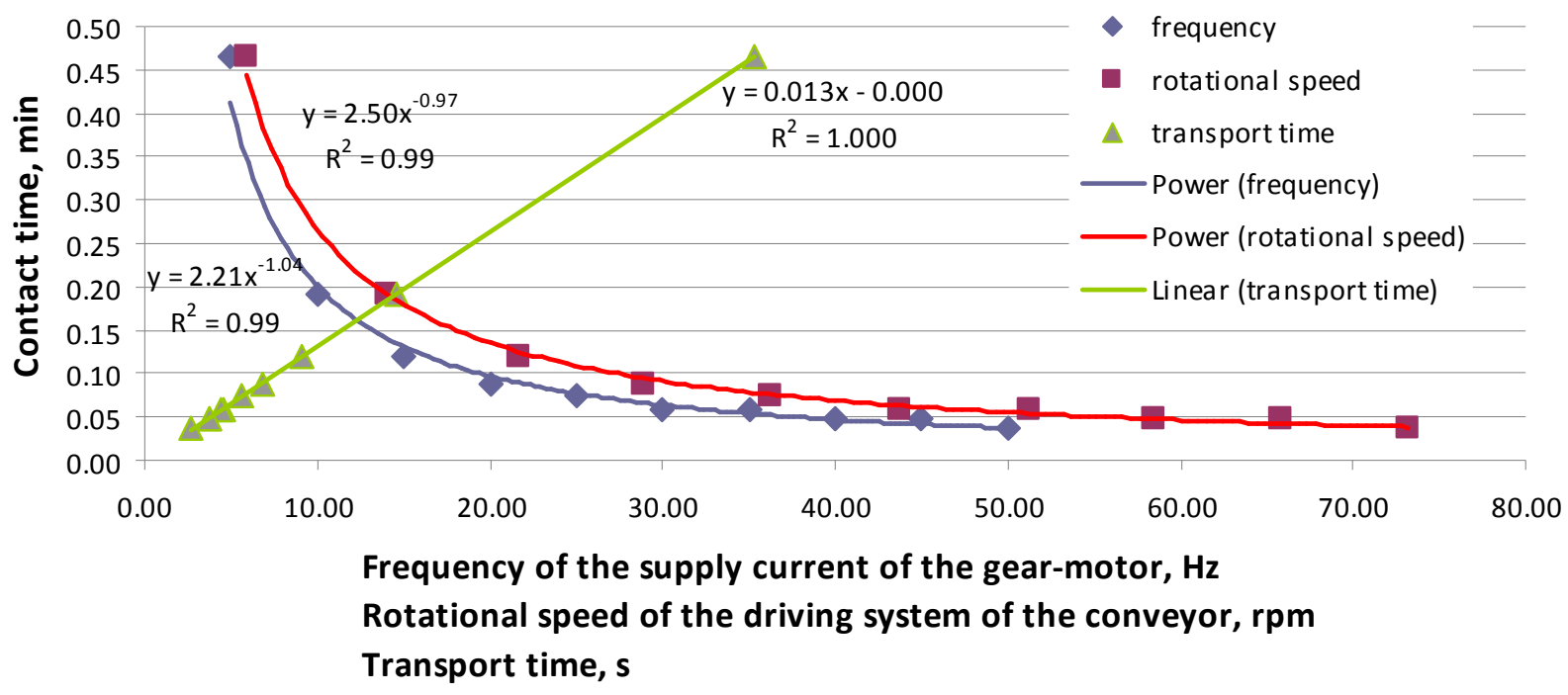

Fig. 2. Variation of the contact time with various parameters 


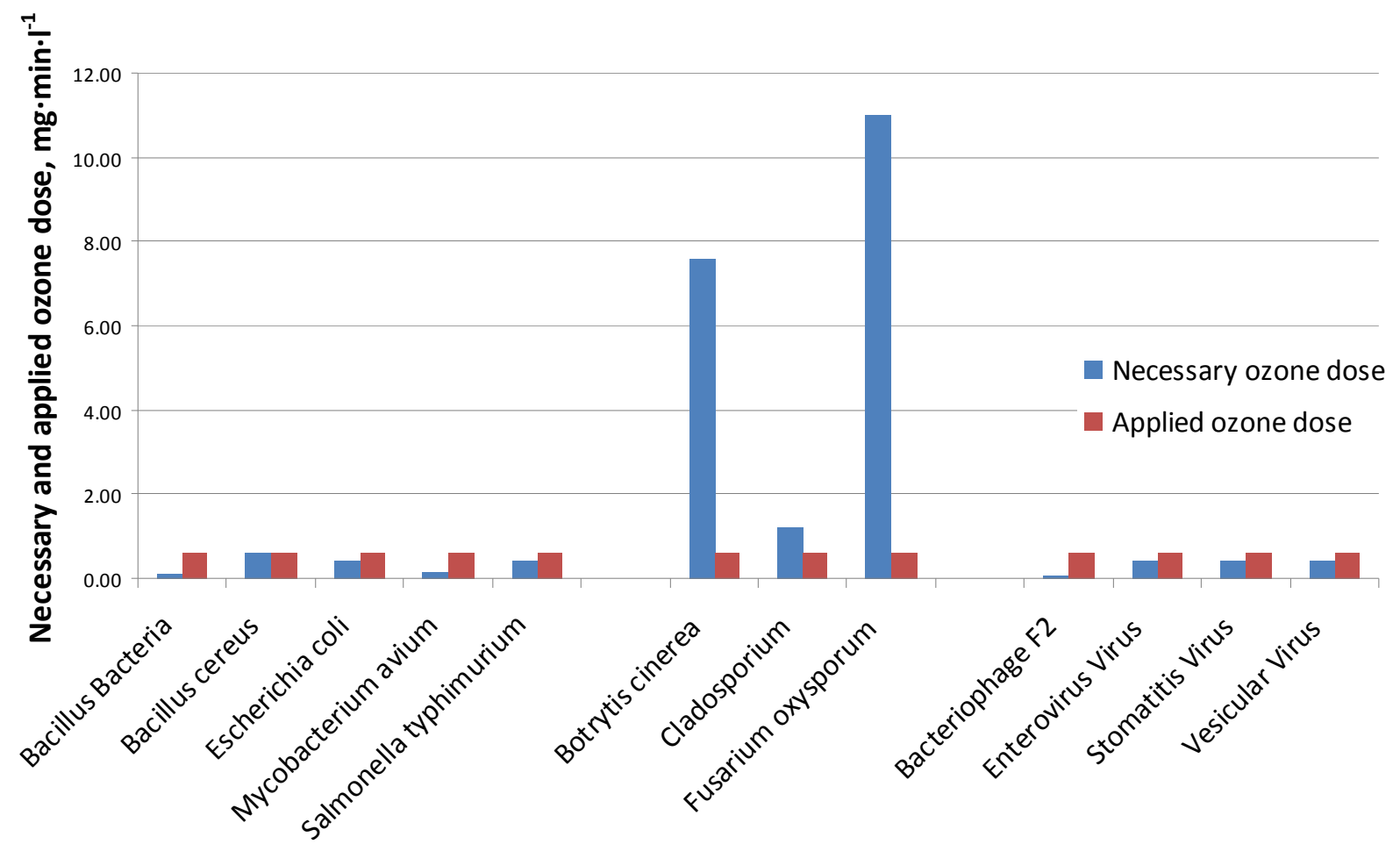

Bacteria, Molds and Viruses

Fig. 3. Comparition between the necessary and applied ozone dose

Figure 3 presents a comparison between the ozone doses necessary for the destruction of the optional pathogenic microorganisms [16] and the ozone doses physically applied by the technical equipment subjected to experimentation.

In Fig. 4 some aspects during the determination of the qualitative indices of the decontamination equipment are shown.
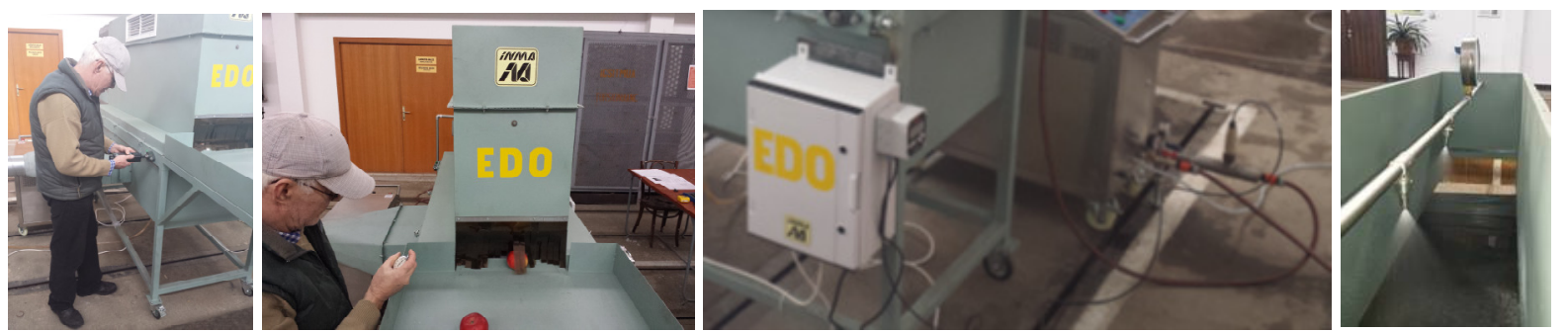

Fig. 4. Determination of the qualitative indices

\section{Conclusions}

1. The coefficient of variation for the distribution of the volume of liquid sprayed along the length of the transport system has a value of $0.15 \%$, which is less than the statistical conventional limit of $5 \%$, below this limit the distribution being considered very homogeneous and the average value of volume is representative. These results shows that the spraying nozzles are properly calibrated by the producer and homogeneously distribute the liquid along the length of the transport system.

2. The contact time of the products with the aqueous ozone solution decreases with the increasing of the frequency of the supply current and, implicitly, of the speed of the gear-motor, which drives the transport system. Also, the contact time decreases with the increasing of the transport speed of the products within the equipment.

3. The applied ozone dose varies directly proportional with the contact time, assuming that the dissolved ozone concentration remains unchanged.

4. Analyzing the experimental data regarding the applied ozone doses necessary for the destruction of the optional pathogenic microorganisms presented in Table 1 and the graphical representation 
from Fig. 3, we can say that the experimented decontamination equipment has the capability to achieve quality indices (maximum applied ozone dose of $0.614 \mathrm{mg} \cdot \mathrm{min} \cdot \mathrm{l}^{-1}$ ) slightly superior (except for molds) to the recommendations in Table 1, in a single pass, without having to repeat the exposure to aqueous ozone.

5. Since molds have a recommendation for superior applied ozone doses, the experimented equipment cannot provide them in a single pass. However, since the equipment is intended to be used within the proposed conditioning technology of horticultural products, prior to UV-C postharvest treatment and temporary storage, UV-C radiation treatment to deal with the molds that have a better resistance is expected.

6. The use of post-harvest treatment methods implying aqueous ozone, single or in combination with UV-C radiation, may be a viable solution to improve the bacteriostatic effect and avoid contamination with toxic residues from the decontamination with chemicals.

\section{Acknowledgements}

The work has been funded by the Ministery of National Education and Research through the National Agency for Scientifical Research and Innovation, within the project entitled „Post-harvest treatment technology of horticultural products intended for fresh consumption, using ozone in aqueous solution”, PN 16240203.

\section{References}

1. Perni S., Liu D.W., Shama G. and Kong M.G. J. Food Prot. 71, 2008, pp. 302.

2. Hinojosa A., Silveira Ac., Ospina M., Char C., Saenz C. and Escalona Vh. Safety of Ready-to-Eat Watercress Using Environmentally Friendly Sanitization Methods. Journal of Food Quality. 36, 2013, pp. 66-76.

3. Hinojosa A., Silveira Ac., Ospina M., Char C., Saenz C. and Escalona Vh. Safety of Ready-to-Eat Watercress Using Environmentally Friendly Sanitization Methods. Journal of Food Quality. 36, 2013, pp. 66-76.

4. López-Gálvez F., Allende A., Selma M.V. and Gil M.I. Prevention of Escherichia coli crosscontamination by different commercial sanitizers during washing of fresh-cut lettuce. Int. J. Food Microbiol. 133, 2009, pp. 167-171.

5. Davies A., Pottage T., Bennett A., Walker J. Gaseous and air decontamination technologies for Clostridium difficile in the healthcare environment. Journal of Hospital Infection, vol. 77, issue 3, 2010, pp. 199-203.

6. Sharma M., Hudson J.B. Ozone gas is an effective and practical antibacterial agent. Am J Infect Control, vol. 36, 2008, pp. 559-563.

7. Moat J., Cargill J., Shone J., Upton M. Application of a novel decontamination process using gaseous ozone. Can J Microbiol, vol. 55, 2009, pp. 928-933.

8. Rice R. G. Ozone in the United States of America - State-of-the-art. Ozone Sci Eng, vol. 21, 1999, pp. 99-118.

9. Federal Register. Secondary direct food additives permitted in food for human consumption, final rule. Fed Regist 66(123), 33829-33830, 2001.

10. Graham D. M. Use of ozone for good processing. Food Technol, 51(6), 1997, pp. 72-75.

11. Kowalski W. J., Bahnfleth W. P., Whittam T. S. Bactercidal effects of high airborne ozone concentrations. Ozone Sci Eng, 20, 1998, pp. 205-221.

12. Kim J. G., Yousef A. E., Chism G. W. Use of ozone to inactivate microorganisms on lettuce. J. Food Safety, 19, 1999a, pp. 17-34.

13. Kim J. G., Yousef A. E., Dave S. Application of ozone for enhancing the microbiological safety and quality of foods: a review. J. Food Prot, 62(9), 1999b, pp. 1071-1087.

14. Kim J. G., Yousef A. E. Inactivation kinetics of foodborne spoilage and pathogenic bacteria by ozone. J. Food Sci, 65, 2000, pp. 521-528.

15. Pruteanu A., Sorica C. Current applications of ozone in food industry. Proceedings of the "5th International Conference on Thermal Equipment, Renewable Energy and Rural Development TERE-RD 2016”, June 2-4, 2016, Golden Sands, Bulgaria, pp. 385-390.

16. Ozone solutions homepage. [online][11.12.2016] Available at: http://www.ozonesolutions.com. 